\title{
Prediction of body weight using appropriate regression model in adult female Malabari goat
}

\author{
R. Chitra ${ }^{1}$, S. Rajendran ${ }^{1}$, D. Prasanna ${ }^{1}$, A. Kirubakaran ${ }^{2}$ \\ 1. Veterinary College and Research Institute, Namakkal, Tamil Nadu - 637 002, India \\ 2. Veterinary University Training \& Research Centre, No. 150, Sathy Road, Veerappan Chatram, Erode, \\ Tamil Nadu - 638004 , India \\ Corresponding author: S Rajendran, email: acrajendran@gmail.com \\ Received: 09-11-201, Accepted: 06-12-2011, Published Online: 06-05-2012 \\ doi: 10.5455/vetworld.2012.409-411
}

\begin{abstract}
Aim: To know the the relationship between body weight and linear body measurements such as body length, height at withers and heart girth in Malabari adult female goats under field conditions.

Materials and Methods: A total of 152 adult female Malabari goats' body weight and body measurements (body length, height at withers and heart girth) were used to develop the step wise multiple regression equations.

Results: The average body weight, body length, height at withers and heart girth were $24.230 .73 \mathrm{~kg}, 59.420 .98 \mathrm{~cm}, 61.02$ $1.03 \mathrm{~cm}$ and $66.541 .09 \mathrm{~cm}$, respectively. Prediction of body weight based on heart girth alone or combined with other body measurements had higher coefficient of determination $\left(\mathrm{R}^{2}\right)$ and lower residual mean square (MSE).

Conclusion: It could be concluded that the prediction model for body weight of Malabari female adult goats with independent variable heart girth can be better fit.

Key words: Body length, Body measurements, Body weight, Heart girth, Height at withers, Malabari goats, Prediction equation
\end{abstract}

\section{To cite this article:}

Chitra R, Rajendran S, Prasanna D, Kirubakaran A (2012) Prediction of body weight using appropriate regression model in adult female Malabari goat, Vet World, 5(7):409-411, doi: 10.5455/vetworld.2012.409-411

\section{I ntroduction}

Goats are one of the main meat producing animals in India. Body weight of the animal is needed for many purposes like feeding and breeding management, for marketing, health care etc. In the field level, weighing facility may not available and visual determination of the body weight of the animals is practiced by farmers which is scientifically inaccurate method of body weight determination.

Biometric measurements have been used to predict the body weight of goats without weighing balance [1-10]. Prediction equation with different combination of body measurements can be used to estimate live body weight for males and females at various ages of a particular breed based on coefficient of determination $\left(\mathrm{R}^{2}\right)[1,6,9,10]$. Malabari or Tellichery is a native goat breed of Kerala and are medium sized animals [11]. The present study was carried out to establish the relationship between body weight and linear body measurements such as body length, height at withers and heart girth in Malabari adult female goats under field conditions.

\section{Materials and Methods}

A total of 152 adult female goats were selected randomly in its breeding tract. Body weight was taken by using the hanging balance. The body length (distance from point of shoulder to pin bone) and heart girth (chest circumference) were measured with a measuring tape, while height at withers (distance from point of withers to toe region) was measured using graduated wooden tape.

Mean and standard error for the body weight and body measurements were calculated. Step wise multiple regression procedure was used to find the combination of body measurements which can explain the maximum variation in the dependent variable, the body weight and regression equation was compared based on coefficient of determination [12]. For comparing equations with unequal number of independent variables, residual mean square was used as a selection criterion to decrease the standard deviation error [12].

\section{Results and Discussion}

The average values for body weight and measure- 
Prediction of body weight using appropriate regression model in adult female Malabari goat

Table-1. Mean ( \pm S.E.) for body weight and linear body measurements

\begin{tabular}{llll}
\hline Body weight(kg) & Body length $(\mathbf{c m})$ & Height at Withers $(\mathbf{c m})$ & Heart Girth(cm) \\
\hline $24.23 \pm 0.73$ & $59.42 \pm 0.98$ & $61.02 \pm 1.03$ & $66.54 \pm 1.09$ \\
\hline
\end{tabular}

Table-2. Regression of body weight on body measurements

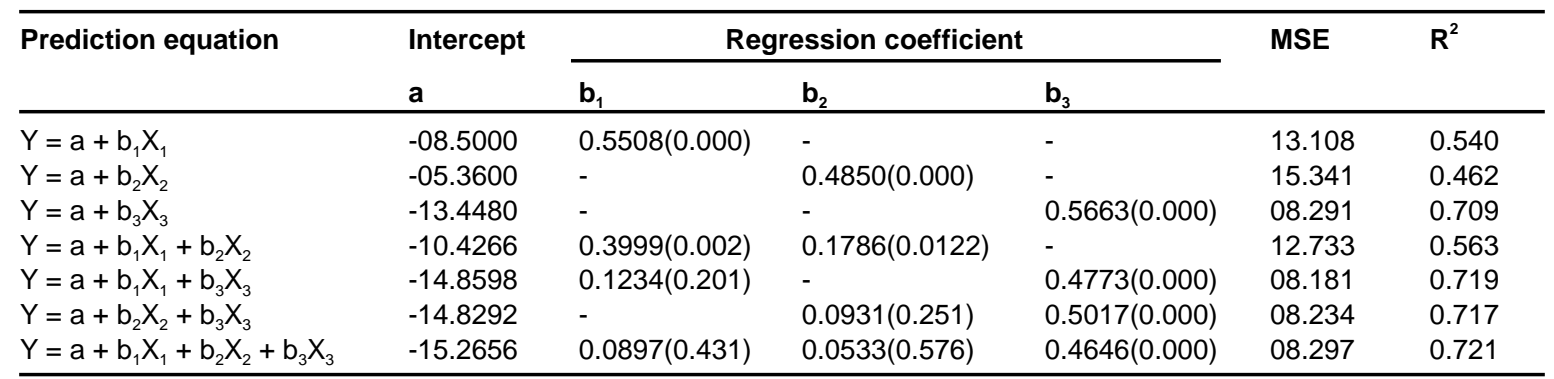

Probability in parentheses: $\mathrm{R}^{2}$ - Coefficient of determination, MSE - Residual mean square, $\mathrm{X}_{1}-$ Body length, $\mathrm{X}_{2}-\mathrm{Height}$ at withers, $\mathrm{X}_{3}$ - Heart girth, $\mathrm{Y}$ - Body weight

ment parameters are shown in Table-1. Regression equations which are predicting the dependent variable body weight from body parameters (body length, height at withers and heart girth), residual mean square and coefficient of determination are presented in Table-2. The coefficient of determination was lower in a regression model constructed by using height at withers $\left(\mathrm{R}^{2}=0.462\right)$ and body length $\left(\mathrm{R}^{2}=0.540\right)$, where as regression equation with heart girth was higher $\left(R^{2}=0.709\right)$. Residual mean square were found to be $15.341,13.108$ and 08.291 for height at withers, body length and heart girth, respectively and the trend was reversed in case of residual mean square when compared to the $\mathrm{R}^{2}$ value.

The coefficient of determination was recorded to be lower $\left(\mathrm{R}^{2}=0.563\right)$ for body length and height at withers combination equation while that of prediction equations with heart girth as one of the independent variable noted to be higher $\mathrm{R}^{2}$ value $(0.719 ; 0.717$ and $0.721)$. The residual mean square was found to be lower in the equations predicting with heart girth as one of the independent variable.

The present study showed that coefficients of determination increased while residual mean square decreased when the heart girth was independent variable. The larger $\mathrm{R}^{2}$ and smaller residual mean square produce better goodness of fit. This is in consonance with the findings of [1,3,8-10].

\section{Conclusion}

By using of body length and height at withers have been reported to be limited in their values as indicators of weight. The coefficient of determination was comparatively higher and also residual mean square was smaller in the equations with heart girth as independent variable. Hence the estimation of the body weight is more accurate when prediction is based on heart girth alone or combination with other body measurements in female adult Malabari goats.

\section{Acknowledgements}

The authors thank Dr. T. V. Aravindakshan, Professor, Department of Animal Genetics and Breeding, College of Veterinary and Animal Sciences, Mannuthy, Thrissur, Kerala for the help and encouragement.

\section{Competing interests}

Authors declare that they have no competing interests.

\section{References}

1. Alade, N. K., Raji, A. O. and Atiku, M. A. (2008). Determination of appropriate model for the estimation of body weight in goats. Journal of Agricultural and Biological Science. 3(4): 52-57.

2. Benyi, K. (1997). Estimation of live weight from chest girth in pure and cross bred West African goats. Tropical Animal Health and Production. 29: 124-128.

3. Bhatacharya, B., Ghoshi, T.K., Duttagupta, R. and Moitra, D.N. (1984). Estimation of body weight in Black Bengal goats from body measurements. Indian Veterinary Journal. 61: 406-408.

4. Chawla, D.S., Nagpal, S. and Bhatnagar, D. S. (1984). Variation in body weight of Beetal and Saanen goats. Indian Journal of Animal Science. 54(7): 711-714.

5. Das, N., Joshi, H. B. and Bisht, G. S. (1990). Prediction of body weight from body measurements in Barbari and Jamnapari goats reared under intensive management system. Indian Veterinary Journal. 67: 347-351.

6. Khan, H., Muhammad, F., Ahmad, R., Nawaz, G., 
Rahimullah and Zubair, M. (2006). Relationship of body weight with linear body measurements in goats. Journal of Agricultural and Biological Science. 1(3): 51-54.

7. Otoikhian, C. S. O., Otoikhian, A. M., Akporhuarho, O. P., Oyefia, V. E. and Isidahomen, C. E. (2008). Body measurement parameters as a function of assessing body weight in goats under on-farm research environment. African Journal of General Agriculture.4(3): 136-140.

8. Singh, P. N. and Mishra, A. K. (2004). Prediction of body weight using conformation traits in Barbari goats. Indian Journal of small Ruminants. 10(2): 173.

9. Thiruvenkadan, A. K. (2005). Determination of bestfitted regression model for estimation of body weight in Kanni Adu kids under farmer's management system.
Livestock Research for Rural Development. Vol. 17,Article\#85.http://www.lrrd.org/lrrd17/7/thir17085.htm.

10. Yakubu, A., Ladokun, A. O. and Adua, M. M. (2011). Bioprediction of Body Weight from Zoometrical Traits of Non-descript Goats using Linear and NonLinear Models in North Central Nigeria. Livestock Research for Rural Development. Volume 23, Article \#130. http://www.lrrd.org/lrrd23/6/yaku23130.htm.

11. Jimcy, J., Raghavan, K. C. and Sujatha, K. S. (2011). Diversity of local goats in Kerala, India, based on morpho-biometric traits. Livestock Research for Rural Development. Volume 23, Article \#119. http://www.lrrd.org/lrrd23/5/jimc23119.htm.

12. Snedecor, S.W. and Cochran, W.G. (1989). Statistical Methods. Eighth edition. Iowa State University Press, USA. 